\title{
Plating versus external fixation of displaced distal radial fractures
}

\begin{abstract}
The purpose of the review was to outline the surgical anatomy, surgical indications, broad surgical options, and to analyse comparative studies of plating versus external fixation looking at the subsequent functional outcomes. A comprehensive literature search over the past 20 years was performed utilising MEDLINE/Pub med, as well as the Hinari programme. There has been a recent trend toward stable internal fixation and more specifically volar locking plates. External fixation has been associated with delayed wrist rehabilitation and a more demanding post operative course. Despite these facts, the results of comparative studies between external fixation and plating initially did not demonstrate a superior outcome one way or the other. The results varied according to whether plating was volar or dorsal as well as if the plates were conventional or locking. The results were generally reported as functional outcome and or complication rates. The majority of comparative studies of plating versus external fixation had variable types of methodological flaws. More recent meta-analysis now demonstrate a trend towards volar plating because of a quicker return to function, lower complication rates and superior DASH and VAS scores as compared with external fixation.
\end{abstract}

Keywords: Plating, External fixation, Distal radial fractures
Volume 2 Issue 2 - 2015

\author{
Cary Fletcher \\ Department of Orthopaedics, St. Ann's Bay Hospital, Jamaica
}

Correspondence: Cary Fletcher, Department of Orthopaedics, St. Ann's Bay Hospital, North East Regional Health Authority, I Seville Road St Ann's Bay, St. Ann, Jamaica, Tel 876-972-2273, Email c.fletch30@yahoo.com

Received: January 02, 2015 | Published: March 10, 2015
Abbreviations: DRUJ, Distal Radio-Ulnar Joint; TFCC, Triangular Fibro-Cartilaginous Complex; AO, Arbeitsgemeinscaft Fur Osteosynthesis Fragen; ROM, Range of Motion; ADL, Activities of Daily Living; DASH, Disabilities of the Arm, Shoulder and Hand; VAS, Visual Analogue Score

\section{Introduction}

The management of distal radial fractures continues to spark controversy and interest. ${ }^{1,2}$ Overall, most of these injuries are due to low energy falls and are stable. Younger patients tend to have a high energy mechanism of injury. 3 The most common form of treatment remains nonsurgical management; however, there are a variety of treatment options available for fractures too unstable for nonoperative management. ${ }^{4-6}$ These include external fixation, percutaneous pinning, internal fixation or a combination. ${ }^{5,7}$ Distal radial fractures occur with a high frequency accounting for approximately one-sixth of all fractures seen in the emergency room. ${ }^{1,8,9}$ Most are as a result of a fall which shows an extra-articular fracture pattern. There is a bimodal distribution in children and the elderly. ${ }^{1}$ Distal radial intra-articular fractures represent an unstable, complex, high energy injury which may be difficult to manage. ${ }^{10,11}$ High energy injuries often cause shear and impaction fractures of the articular surface.12 High energy injuries seen in young or active elderly patients require effective treatment in order to achieve restoration of wrist function near preinjury levels. ${ }^{13}$

A review of the most recent literature using PUBMED as a search engine was utilised with a focus on comparative studies. The WHO initiative Hinari was also utilised to gain free online access to numerous journals. This review discusses surgical anatomy, surgical indications, comparisons between open and closed treatment, dorsal versus volar approaches for open treatment, goals of treatment and functional outcomes of external fixation versus various plating techniques.

\section{Discussion}

The surgical anatomy of the distal radius and its articulations are quite complex. Any surgeon operating in this area must have thorough anatomical knowledge. ${ }^{13}$ There are three independent articular surfaces: the scaphoid facet, lunate facet and sigmoid notch are found on the distal radius. ${ }^{8,13}$ The scaphoid facet along with the radial styloid forms the lateral column, and the medial aspect of the distal radius consists of the lunate facet and sigmoid notch. ${ }^{13}$ The lunate facet is almost perpendicular to the sigmoid notch and articulates with the distal ulna to form the distal radioulnar joint (DRUJ). The close proximity of the sigmoid notch to the lunate suggests that injury to this column involves the DRUJ. ${ }^{13}$ Malalignment of the radiocarpal or ulnocarpal or DRUJ lead to wrist dysfunction. ${ }^{8,14}$ The volar surface is relatively flat and covered proximally by pronator quadratus, whereas the dorsal surface is convex. The extensor tendons are separated from the bony surface by the floor of the extensor retinaculum and periosteum. ${ }^{8,14}$ The triangular fibro-cartilaginous complex (TFCC) which is an important stabiliser of the DRUJ is sensitive to trauma and degenerative changes. ${ }^{8}$

The AO system with 27 categories is the most detailed inclusive classification of distal radial fractures. ${ }^{12}$ When reduced to three categories - types A, B, and C-there is a significant increase in the inter observer agreement. ${ }^{15} \mathrm{AO}$ Type $\mathrm{A}$ is extra-articular metaphyseal injuries usually due to bending. Type B are partial intra-articular fractures resulting from shear or impaction injuries, where part of the articular surface remains in continuity with the metaphysis, which is a significant contributor to stability. The AO Type $\mathrm{C}$ fractures are complex articular injuries which are usually high energy involving a combination of shear and impaction forces.

Standard x-rays are often inadequate to fully evaluate fractures which are highly comminuted, displaced complex intra-articular 
fractures. Computed Tomography is required to provide adequate information as part of the pre-operative planning to assess radiocarpal articular step-off and gap displacement which are predictors of osteoarthritis. ${ }^{16}$ It may also detect volar and or dorsal displacement not evident on $\mathrm{x}$-ray. ${ }^{14,17}$ Unstable injuries are characterised by an inability to achieve or maintain a reduction ${ }^{13}$ and require surgical management. ${ }^{4,17}$ Indications for surgical fixation have traditionally been post reduction films showing radial shortening, dorsal angulation greater than $10^{\circ}$ and intra-articular step-off greater than $2 \mathrm{~mm} \cdot .^{10,17}$ Lichtman et al. ${ }^{18}$ in analysing the literature recommended these parameters for surgical indications. Mc queen et al. ${ }^{19}$ in their study of mal united distal radial fractures demonstrated that grip strength, range of motion (ROM) and ability to perform ADL were significantly worse with dorsal angulation greater than $12^{\circ}$ compared with those less than $10^{\circ} .{ }^{19}$

Gofton and Liew ${ }^{6}$ found that radial shortening followed by dorsal comminution were the most important predictors of instability. Shortening of the distal radius greater than $2.5 \mathrm{~mm}$ or a dorsal tilt greater than ten degrees significantly increases the axial loading through the ulnar shaft with decreasing contact of the scaphoid and lunate with the distal radius. ${ }^{20}$ The increased dorsal tilt results in incongruity of the DRUJ with subsequent tightening of the interosseus membrane which limits forearm rotation. ${ }^{21}$ Knirk and Jupiter ${ }^{22}$ found that a $2 \mathrm{~mm}$ displacement may cause joint degeneration resulting in pain and stiffness; however Trumble et al. ${ }^{23}$ stated that only $1 \mathrm{~mm}$ was required for this to happen. An accurate means of predicting instability allows for timely definitive surgical treatment, avoidance of unnecessary remanipulation and reduced malunion rates. ${ }^{24}$ Most agree that the majority of malunions do not allow for a painless wrist or full ROM. $1^{7}$

Colles and other great physicians in the 19th century believed that all distal radial fractures were straight forward and had good outcome regardless of treatment. ${ }^{17}$ Literature over the next century led many to believe that treatment was a solved problem. ${ }^{3}$ Nowadays the management of unstable injuries remains controversial..$^{2,11,14,25}$ The treatment choice is based on fracture type, fracture stability, patient characteristics and demands, the treating surgeons' experience and preference. ${ }^{8,12,17,26}$ There has recently been a significant explosion of new treatment options including plate designs. This explosion has mainly been implant and industry driven with a concomitant lack of evidence-based practice..$^{27}$ Interest is due to its high incidence and a developing understanding of outcome variables in addition to the influence of the treatment technology. ${ }^{1}$

The goal of treatment is to restore length, articular congruity, radial inclination and maintenance of the DRUJ. ${ }^{5}$ Clinical goals are to restore wrist function and limit pain at the lowest possible cost. 8 Achievement of as near anatomic position is required in order to optimise function ${ }^{6,10,13,24}$ and to minimise future degenerative disease with subsequent disability. ${ }^{1}$ Although stable fixation allows for early rehabilitation there must be a balance between stable fixation and soft tissue disruption. ${ }^{17}$ The ideal surgical technique must be reliable and can be mastered by most. ${ }^{10,28}$

Recently there has been a significant bias towards stable internal fixation which has been touted by several authors as the treatment of choice, ${ }^{3,29}$ and more specifically volar locking plates..$^{10,26,30,31}$ This trend is partially due to an increased understanding of the DRUJ. ${ }^{3}$ Koval $^{25}$ searched the American Board of Orthopaedic Surgery Part II database to evaluate changes in treatment over times. He found that in $1999,58 \%$ were treated with percutaneous fixation and by 2007 , $81 \%$ of the distal radial fractures had open treatment. Koval theorised that this was due to training practices, younger surgeons constantly looking to use new technology, less demanding postoperative care compared with external fixation and less difficulty in commencing early rehabilitation.

Despite this, external fixation continues to be employed ${ }^{2,5,7,32}$ because it is minimally invasive and a long standing tool in the surgeons' armamentarium. ${ }^{2,11,26}$ It is still the standard technique at many institutions. ${ }^{28,33}$ External fixation may be successfully used in inexperienced hands or by surgeons out of their comfort zones using the newer plating systems. ${ }^{2}$ It is usually used in conjunction with K-wires and bone grafting while also allowing for concomitant assessment of ligaments and articular surface inspection via arthroscopic assisted reduction. ${ }^{11}$ The recommendation for arthroscopy as an adjunct has been deemed to be weak based on Lichtman et al. ${ }^{18}$ literature review. The addition of K-wires reduces the distraction forces required for the external fixator to maintain the reduction. ${ }^{8} \mathrm{~K}$-wires may also be used in conjunction with a volar buttress plate when there is a sagittal spilt or volarly displaced fragment. ${ }^{2,734}$

Broadly speaking, there are two acceptable treatment methods: external fixation and plating. ${ }^{10}$ Grewal et al. ${ }^{35}$ prospectively randomised 62 patients to open reduction and dorsal plate fixation versus external fixation supplemented with $\mathrm{K}$-wiring. The dorsal plate group had a significantly higher complication rate including pain, decreased grip strength and increased tourniquet time however; there was no difference in SF 36 or DASH scoring systems. Their recommendation was to avoid the use of dorsal plating. Kreder et al. ${ }^{36}$ in their randomised, prospective study found that indirect reduction and percutaneous fixation was associated with a quicker, superior return to function at six months using SF 36 scores, compared to plating in 179 patients. He proposed that achieving a congruent articular surface by indirect means accounted for his results. This is in contrast to Leung ${ }^{10}$ who achieved superior results with conventional plating in 70 patients when compared to 74 patients with external fixation using the Gartland and Werley clinical grading system and the arthritis grade. There was no difference between the groups when clinical parameters including ROM and grip strength were used. In analysing his results Leung noted that Kreder et al. ${ }^{36}$ primarily used a dorsal approach in their plating group, whereas only $17 \%$ of patients in his plating group were done via a dorsal approach.

Leung et al. ${ }^{10}$ felt that limited usage of dorsal plating or early removal improved his results in the plating group. He also disagreed with Kreder et al. who had stated in their study, that follow up beyond one year was unnecessary because functional scores are stable beyond that point. Leung et al. ${ }^{10}$ used the Garland and Werley scoring system as well as the modified Green and O'Brien system and noted continued improvement in clinical assessment up to 24 months following intervention. Abramo et al. ${ }^{33}$ also found improvement in clinical and scoring systems beyond one year.

Chen and Jupiter ${ }^{3}$ also disagreed with Kreder's et al. view and stated that midterm follow up may have independent value and should be continued and reported. Chen and Jupiter ${ }^{3}$ also noted that in Kreder's et al. study it was unclear whether occupational therapy was done in the ORIF group as this may have made a difference. Abramo et al. ${ }^{4}$ found that regardless of the type of treatment, most patients had some degree of discomfort and decreased function in the first year. Despite the growing popularity of locking plates, the studies 
supporting its use are often observational and retrospective..$^{30,31,37}$ Volar plates provide distal fixation via screws, smooth or locked pegs. These fixed elements attach into the plate and provide fixation into the distal fragment by buttressing or interference. ${ }^{13,30}$ Volar plates were introduced as a solution for dorsal fractures because of disappointing results with dorsal fixed angled plates. ${ }^{30}$ In this regard, there are less patient related complications..$^{30,31,37}$ The locking screws avoid the need for bone purchase and reduce loosening by providing a scaffold under the articular surface. ${ }^{13,37}$ This avoids screw penetration of the dorsal cortex and decreases the rates of tendon complications. ${ }^{3,30,31}$

Early wrist and finger ROM is facilitated via stable fixation ${ }^{30,37}$ because it is said not to tether muscle, tendon and capsule unlike spanning external fixation. ${ }^{27}$ Despite these theoretical advantages of volar plate fixation, comparative studies initially did not show any clear superiority between volar plating and external fixation. ${ }^{38,39}$ This was despite superior radiological results in the volar plating group in Wright et al..$^{38}$ study. In fact, Koenig et al..$^{40}$ only found a marginal difference between volar plating and casting for potentially unstable fracture patterns. Others have documented superior ROM, grip strength and DASH scores with volar plating when compared to other forms of fixation in the first few months. ${ }^{26,29}$ The radial column plate and external fixation were also shown to produce good subjective and objective results and were also viable options. ${ }^{26}$ This was the first time fragment specific fixation (radial column plate) entered the comparative literature. ${ }^{26}$ Volar plates when compared to other forms of fixation, may offer better fixation because of early ROM protocols which allow for rapid incorporation of the injured limb during ADL. ${ }^{26,29}$ It must be strongly considered in patients requiring rapid return to function, which is partly responsible for the recent enthusiasm for volar plating. ${ }^{26,29}$

The majority of randomised controlled studies prior to the year 2000, suffered from methodological deficiencies. Most had small patient numbers and this evidence was weak according to the Cochrane meta-analysis reports. ${ }^{41}$ Handoll and Madhok $^{42}$ analysed 44 randomised trials which despite providing evidence for the effectiveness of external fixation, its precise role was not established. Historically, there was insufficient data to perform a scientific metaanalysis because of the poor quality of the studies and lack of a uniform method of outcome assessment. Data from comparative trials suggested that external fixation was superior to closed reduction and casting and internal fixation, but no studies directly comparing open reduction, internal fixation and external fixation using a contemporary comparison group was found. ${ }^{43}$

Margeliot et al. ${ }^{44}$ performed a meta-analysis looking at outcome of external fixation versus plating in terms of grip strength, wrist ROM, x-ray alignment, pain and complication rates. There were 28 external fixation studies and 18 internal fixation studies. All studies had significant heterogenicity which adversely affects the precision of results. Although there were higher complication rates with external fixation including increased infection rates, hardware failure and neuritis, they concluded there was no evidence to support usage of one method versus other. Due to the variation in fracture patterns, bone defect sizes and bone quality in different patients, it is difficult to standardize management because of heterogeneous treatment groups. ${ }^{10,33}$ The majority of existing comparative studies involve external fixation versus plating, either dorsal or volar, and includes fractures which span the extremes of severity which makes it difficult for the reader to draw any conclusion..$^{29}$
Richard et al. ${ }^{45}$ treated 59 patients with external fixation and 56 patients with volar plating. They found significantly superior ROM in flexion/extension and pronation/supination arcs, as well as better VAS and DASH scores in the plating group. In a separate study, he also noted that the external fixation group had significantly higher complication rates including an increased incidence of radial shortening resulting in an increased incidence in positive ulnar variance. ${ }^{46}$ Esposito et al. ${ }^{47}$ conducted a meta-analysis of randomised controlled studies up to the year 2011. He found that plating resulted in lower DASH scores, lower infection rates and a superior restoration of radial length in comparison to external fixation.

There remain certain persistent limitations in the recent comparative studies between external fixation and plating. There is often lack of blinding because the person performing the surgery is often the same person examining the patient afterwards. ${ }^{46}$ There is also the potential for selection bias however personal preference as opposed to the fracture patterns is often the bigger factor affecting the implant choice. ${ }^{46}$ Xie et al ${ }^{48}$ in a comprehensive literature review could only find 10 randomised controlled studies comparing plating and external fixation with at least 1 year follow up to include in his meta-analysis. Allocation concealment was only adequately reported for 4 of the studies. ${ }^{48}$ Although the best available evidence is via a meta-analysis of randomised controlled studies, heterogenicity in patient age will occur because it is impossible to match cohorts completely, and differences in fracture type-specific effects on the different implant options have not been established..$^{48}$

\section{Conclusion}

The most recent data suggests that volar plating is associated with reduced pain, superior ROM in all directions and improved functional scores. There is also level one evidence demonstrating that locked volar plating is associated with better patient-reported outcomes compared to external fixation in the first three months postoperatively. It is therefore advantageous in patients requiring an accelerated functional recovery and also associated with fewer complications.

\section{Acknowledgment}

Kaye P. Lambert Fletcher: For the provision of important technical assistance.

\section{Reference}

1. Ehrlich GE. Low back pain. Bull World Health Organ. 2003;81(9):671676.

2. Ilyas AM, Jupiter JB. Distal radius fractures - classification of treatment and indications for surgery. Orthop Clin North Am. 2007;38(2):167-173.

3. Vasenius J. Operative treatment of distal radius fractures. Scand J Surg. 2008;97(4):290-297.

4. Chen NC, Jupiter JB. Management of Distal Radial Fractures. J Bone Joint Surg Am. 2007;89(9):2051-2062.

5. Abramo A, Kopylov P, Tagil M. Evaluation of a treatment protocol in distal radius fractures: a prospective study in 581 patients using DASH as outcome. Acta Orthop. 2008;79(3):376-385.

6. Capo JT, Swan KG, Tan V. External fixation techniques for distal radius fractures. Clin Orthop Relat Res. 2006;445:30-41.

7. Gofton W, Liew A. Distal radius fractures: nonoperative and percutaneous pinning treatment options. Orthop Clin North Am. 2007;38(2):175-185. 
8. Payandeh JB, McKee MD. External fixation of distal radius fractures. Orthop Clin North Am. 2007;38(2):187-192.

9. Nijs S, Broos PL. Fractures of the distal radius: a contemporary approach. Acta Chir Belg. 2004;104(4):401-412.

10. Lindau T, Hagberg L, Adlercreutz C, et al. Distal radioulnar instability is an independent worsening factor in distal radial fractures. Clin Orthop Relat Res. 2000;(376):229-235.

11. Leung F, Tu YK, Chew WY, et al. Comparison of external and percutaneous pin fixation with plate fixation for intra-articular distal radial fractures. A randomized study. J Bone Joint Surg Am. 2008;90(1):16-22.

12. Xu GG, Chan SP, Puhaindran ME, et al. Prospective randomised study of intra-articular fractures of the distal radius: comparison between external fixation and plate fixation. Ann Acad Med Singapore. 2009;38(7):600606.

13. Trumble TE, Culp RW, Hanel DP, et al. Instructional Course Lectures, The American Academy of Orthopaedic Surgeons - Intra-Articular Fractures of the Distal Aspect of the Radius. J Bone Joint Surg Am. 1998;80:582-600.

14. Nana AD, Joshi A, Lichtman DM. Plating of the Distal Radius. J Am Acad Orthop Surg. 2005;13(3):159-171.

15. Mader K, Pennig D. The treatment of severely comminuted intra-articula fractures of the distal radius. Strat Traum Limb Recon. 2006;1(1):2-17.

16. Andersen DJ, Blair WF, Steyers CM, et al. Classification of distal radius fractures: an analysis of interobserver reliability and intraobserver reproducibility. J Hand Surg Am. 1996;21(4):574-582.

17. Pruitt DL, Gilula LA, Manske PR, et al. Computed tomography scanning with image reconstruction in evaluation of distal radius fractures. $J$ Hand Surg Am. 1994;19(5):720-727.

18. Simic PM, Weiland AJ. Fractures of the distal aspect of the radius: changes in treatment over the past two decades. Instr Course Lect. 2003;52:185-195.

19. Lichtman DM, Bindra RR, Boyer MI, et al. Treatment of distal radius fractures. J Am Acad Orthop Surg. 2010;18(3):180-189.

20. McQueen M, Caspers J. Colles fractures: Does the anatomical result affect the final function?: J Bone Joint Surg Br. 1988;70(4):649-651.

21. Short WH, Palmer AK, Werner FW, et al. A biomechanical study of distal radial fractures. J Hand Surg Am. 1987;12(4):529-534.

22. Adams BD. Effects of radial deformity on distal radioulnar joint mechanics. J Hand Surg Am. 1993;18(3):492-498.

23. Knirk LJ, Jupiter BJ. Intra-articular fractures of the distal end of the radius in young adults. J Bone Joint Surg Am. 1986;68(5):647-659.

24. Trumble TE, Schmitt SR, Vedder NB. Factors affecting functiona outcome of displaced intra-articular distal radius fractures. J Hand Surg Am. 1994;19(2):325-340.

25. Mackenney PJ, McQueen MM, Elton R. Prediction of instability in distal radial fractures J Bone Joint Surg Am. 2006;88(9):1944-1951.

26. Koval KJ, Harrast JJ, Anglen JO, et al. Fractures of the distal part of the radius. The evolution of practice over time. Where's the evidence? J Bone Joint Surg Am. 2008;90(9):1855-1861.

27. Wei DH, Raizman NM, Bottino CJ, et al. Unstable distal radial fractures treated with external fixation, a radial column plate, or a volar plate. A prospective randomized trial. J Bone Joint Surg Am. 2009;91(7):15681577.

28. Martineau PA, Berry GK, Harvey EJ. Plating for distal radius fractures Orthop Clin North Am. 2007;38(2):193-201.
29. Hayes AJ, Duffy PJ, McQueen MM. Bridging and non-bridging external fixation in the treatment of unstable fractures of the distal radius: a retrospective study of 588 patients. Acta Orthop. 2008;79(4):540-547.

30. Rozental TD, Blazar PE, Franko OI, et al. Functional outcomes for unstable distal radial fractures treated with open reduction and internal fixation or closed reduction and percutaneous fixation. A prospective randomized trial. J Bone Joint Surg Am. 2009;91(8):1837-1846.

31. Orbay J. Volar plate fixation of distal radius fractures. Hand Clin 2005;21(3):347-354

32. Anakwe R, Khan L, Cook R, et al. Locked volar plating for complex distal radius fractures: Patient reported outcomes and satisfaction. $J$ Orthop Surg Res. 2010;5:51.

33. Atroshi I, Brogren E, Larsson GU, et al. Wrist-bridging versus nonbridging external fixation for displaced distal radius fractures: a randomized assessor-blind clinical trial of 38 patients followed for 1 year. Acta Orthop. 2006;77(3):445-453.

34. Abramo A, Kopylov P, Geijer M, et al. Open reduction and interna fixation compared to closed reduction and external fixation in distal radial fractures: a randomized study of 50 patients. Acta Orthop. 2009;80(4): $478-485$

35. Arora J, Kapoor H, Malik A, et al. Closed reduction and plaster cast immobilization versus external fixation in communited intra-articular fractures of distal radius. Indian J Ortho. 2004;38(2):113-117.

36. Grewal R, Perey B, Wilmink M, et al. Randomized prospective study on the treatment of intra-articular distal radius fractures: open reduction and internal fixation with dorsal plating versus mini open reduction, percutaneous fixation, and external fixation. J Hand Surg Am. 2005;30(4):764-772.

37. Kreder HJ, Hanel DP, Agel J, et al. Indirect reduction and percutaneous fixation versus open reduction and internal fixation for displaced intraarticular fractures of the distal radius: a randomised, controlled trial. $J$ Bone Joint Surg Br. 2005;87(6): 829-836.

38. Chung KC, Watt AJ, Kotsis SV, et al. Treatment of unstable distal radial fractures with the volar locking plating system. J Bone Joint Surg Am. 2006;88(12): 2687-2694.

39. Wright TW, Horodyski M, Smith DW. Functional outcome of unstable distal radius fractures: ORIF with a volar fixed-angle plate versus external fixation. J Hand Surg Am. 2005;30(2):289-299.

40. Egol K, Walsh M, Tejwani N, et al. Bridging external fixation and supplementary Kirschner-wire fixation versus volar locked plating for unstable fractures of the distal radius. A randomised, prospective trial. $J$ Bone Joint Surg Br. 2008;90(9):1214-1221.

41. Koenig KM, Davis GC, Grove MR, et al. Is early internal fixation preferred to cast treatment for well-reduced unstable distal radial fractures? J Bone Joint Surg Am. 2009;91(9):2086-2093.

42. Handoll HH, Madhok R. Surgical interventions for treating distal radial fractures in adults. Cochrane Database Syst Rev. 2003;3:CD003209.

43. Handoll HH, Madhok R. Managing fractures of the distal radius in adults. Clinical and research implications from systematic reviews of existing trials. Acta Orthop Scand. 20002;Suppl 73(305):45-48.

44. Paksima N, Panchal A, Posner MA, et al. A meta-analysis of the literature on distal radius fractures: review of 615 articles. Bull Hosp Jt Dis. 2004;62(1-2):40-46.

45. Margaliot Z, Haase SC, Kotsis SV, et al. A meta-analysis of outcomes of external fixation versus plate osteosynthesis for unstable distal radius fractures. J Hand Surg Am. 2005;30(6):1185-1199. 
46. Richard MJ, Wartinbee DA, Riboh J, et al. Analysis of the complications of palmer plating versus external fixation for fractures of the distal radius. J Hand Surg Am. 2011;36(10):1614-1620.

47. Richard MJ, Wartinbee DA, Miller M, et al. Comparative analysis of the complication profile following palmer plating versus external fixation of fractures of the distal radius. The Duke Orthopaedic Journal. 2010 2011;1(1):1-7.
48. Esposito J, Schemitsch EH, Saccone M, et al. External fixation versus open reduction with plate fixation for distal radius: A meta-analysis of randomised controlled trials. Injury. 2013;44(4):409-416.

49. Xie X, Xie X, Shen L, et al. Comparison of internal and external fixation of distal radial: a meta-analysis of randomised controlled trials. Acta Orthop. 2013;84(3):286-291. 